\title{
Monitoring Piscirickettsia salmonis by denaturant gel electrophoresis and competitive PCR
}

\author{
S. Heath ${ }^{1}$, S. Pak ${ }^{1}$, S. Marshall ${ }^{2}$, E. M. Prager ${ }^{1}$, C. Orrego ${ }^{1,2, *}$ \\ ${ }^{1}$ Conservation Genetics Laboratory, Department of Biology, San Francisco State University, 1600 Holloway Avenue, \\ San Francisco, California 94132, USA \\ ${ }^{2}$ Instituto de Biología, Casilla 4059, Universidad Católica de Valparaíso, Valparaíso, Chile
}

\begin{abstract}
Reported strains of Piscirickettsia salmonis, a pathogen of salmonid fishes, were analyzed by amplifying part of the internal transcribed spacer (ITS) of the ribosomal RNA (rRNA) operon followed by denaturing gradient gel electrophoresis (DGGE) of the amplicons. All amplified fragments differing in sequence were distinguished by migration during DGGE. A simpler format, constant denaturant gel electrophoresis (CDGE), allowed the same diagnostic distinctions among strains. Sampling during 1997 and 1998 of salmonids from 5 different sites on and near Chiloé Island in southern Chile displaying piscirickettsiosis revealed only $P$. salmonis resembling LF-89, the type strain first isolated in 1989. These observations are encouraging for control strategies, which might otherwise be compromised by unpredictable shifts of $P$. salmonis types in salmon farms. A competitive PCR assay offered insight about the power of PCR for quantification and about specific tissue invasiveness by this intracellular pathogen. This approach revealed that the PCR could amplify approximately 1 to $10 P$. salmonis genome equivalents against a background of $>99.9 \%$ salmonid DNA. It also raised the possibility that the salmonid brain is an important site for $P$. salmonis survival, with its bacterial load in 1 individual having been about 100 times the loads observed in liver and kidney. Pathogen detection by competitive PCR in a surface seawater sample from a netpen in use indicated a density of about 3000 to $4000 P$ salmonis cells (or their DNA remnants) $\mathrm{l}^{-1}$ Such quantitative estimates should aid decisions about disease prevention and management as, for example, choice of netpen sites following fallow periods and certification of ova, which are known conduits of infection.
\end{abstract}

KEY WORDS: Piscirickettsia salmonis - Genetic diversity · DGGE · CDGE · Competitive PCR

\section{INTRODUCTION}

In the late 1980 s salmon aquaculture in the fiords of southern Chile faced the emergence of an infectious disease of unknown origin. Symptoms of the disease initially reported in coho salmon Oncorhynchus kisutch were evident after fish underwent transfer to salt water (Bravo \& Campos 1989). A microbial agent was isolated (Fryer et al. 1990, Cvitanich et al. 1991) and further characterized as a novel intracellular organism, Piscirickettsia salmonis (type strain LF-89= ATCC VR 1361), belonging to the gamma subdivision of the proteobacteria (Fryer et al. 1992, Fryer \& Mauel 1997, Mauel et al. 1999). The agent survived in salt water and less well in fresh water (Lannan \& Fryer

•Corresponding author. E-mail: cob@sfsu.edu
1994): it was horizontally transmissible by contact and cohabitation in both environments (Cvitanich et al. 1991, Almendras et al. 1997), with 1 observation of vertical transmission having been reported (Almendras \& Fuentealba 1997). Suspicion of intermediate vectors in the transmission of $P$. salmonis has been raised (Almendras \& Fuentealba 1997). Stress resulting from husbandry practices otherwise considered normal and from environmental conditions has been highlighted as important in the manifestation of the disease (Almendras \& Fuentealba 1997, Olsen et al. 1997).

Piscirickettsiosis or salmonid rickettsial septicemia soon became evident in other salmonids (Atlantic salmon Salmo salar and rainbow trout Oncorhynchus mykiss) in both the northern and southern hemispheres (Fryer \& Lannan 1996, Almendras \& Fuentealba 1997, Olsen et al. 1997, Jones et al. 1998). The 
microbial etiology of these outbreaks has been confirmed by determination of close phylogenetic affiliations to Piscirickettsia salmonis LF-89 (Mauel et al. 1996, 1999), serological criteria (Olsen et al. 1997) and comparative biochemistry of the microbial antigens (Jones et al. 1998). However, severe epizootics of $P$. salmonis occur only in the fish farms of southern Chile, while outbreaks of the organism in other parts of the world have been less pronounced and sporadic (for reviews, see Fryer \& Lannan 1996, House et al. 1999). Other rickettsia-like organisms, different from $P$. salmonis but causing similar disease symptoms, have become evident in Chilean aquaculture (Cvitanich et al. 1995, V. Henríquez, C.O. \& S.M. unpubl.), but there are as yet no molecular genetic data to shed light on their orıin.

We have exploited amplification of the internal transcribed spacer (ITS) region of the ribosomal RNA (rRNA) operon of Piscirickettsia salmonis (Marshall et al. 1998) with 3 objectives in mind: (1) to ascertain further the degree of variation existing in this genetic region among the $P$. salmonis strains or lineages reported in the literature; (2) to establish a molecular assay that could readily monitor the lineages of the pathogen that emerge seasonally in the salmon farms in Chile; and (3) to develop an assay for assessing the number of genome copies of the microbe in environmental samples as well as in different tissues of the host during infection episodes. The first 2 objectives were accomplished by electrophoresis in denaturing polyacrylamide gels (Fischer \& Lerman 1983, Hovig et al. 1991), in which PCR amplicons differing in sequence migrate distinct distances in the presence of denaturants as a result of differences in DNA stability. The third objective was accomplished by competitive PCR (Gilliland et al. 1990), which involves co-amplification of the target of interest and known quantities of a mimic fragment amplifiable by the same primer pair but yielding a product of a different length.

\section{MATERIALS AND METHODS}

Bacterial strains and natural samples. DNA extracts from Piscirickettsia salmonis LF-89 and EM-90 (the latter isolated in Chile from Atlantic salmon) came from the lab collection (Marshall et al. 1998). DNA samples from $P$. salmonis strains SLGO-94 (rainbow trout) and C1-95 (coho salmon), both from Chile, as well as from ATL-4-91 (British Columbia, Canada, netpen-raised Atlantic salmon) and NOR-92 (Norway, netpen-raised Atlantic salmon) were donated by $M$. J. Mauel. These strains are listed by Mauel et al. (1996, 1999) and House et al. (1999) along with additional information on their biological and institutional origins.
Visibly infected tissues of coho salmon and rainbow trout afflicted with piscirickettsiosis were received from 5 different salmon farms and 1 unknown location on and near Chiloé Island (encompassing the sea to the east of the island) in the 1997 and 1998 seasons and kept frozen in HN buffer (Marshall et al. 1998). Sampling of surface seawater (4 to 5 l) from netpens in the Caucahue Channel in the Ancud Gulf, northeast of Chiloé Island, was done essentially as by Massana et al. (1997). Prefiltration of the water was through a Whatman GF/A glass microfiber filter (1.6 $\mu \mathrm{m}$ pore size, $47 \mathrm{~mm}$ diameter, Clifton, New Jersey, USA), and the picoplankton remaining in the filtrate was collected on a Sterivex filtration device $(0.22 \mu \mathrm{m}$ pore size, Millipore, Bedford, Massachusetts, USA) by means of a peristaltic pump. The GF/A filter was changed 2 to 3 times per sample to permit timely filtration of the desired volumes through the Sterivex device. Hose lines were washed thoroughly with tap water between filtrations. Immediately after picoplankton collection, storage buffer $(1.8 \mathrm{ml}, 40 \mathrm{mM}$ EDTA, $50 \mathrm{mM}$ Tris $-\mathrm{HCl}$ [pH 8.0], 0.75 $\mathrm{M}$ sucrose) was added to the Sterivex chamber (which includes the nonremovable Millipore filter) and the chamber was then kept at $<-20^{\circ} \mathrm{C}$ until nucleic acid extraction.

DNA extraction and PCR amplification. DNA was released from tissues by the Chelex method and $1 \mu \mathrm{l}$ used in PCR (total reaction volume, $12.5 \mu \mathrm{l}$ ) with primer pairs RTS1/RTS2 or RTS1/RTS4 complementary to the ITS as described previously (Marshall et al. 1998). For samples to be evaluated by competitive PCR, biopsies of $<0.25 \mathrm{mg}$ were collected at the end of $200 \mu$ pipette tips and submerged in $100 \mu \mathrm{l}$ of the Chelex bead suspension.

Extraction of nucleic acids from samples collected with Sterivex devices was initiated by the addition of lysozyme (1 $\mathrm{mg} \mathrm{ml}^{-1}$ final concentration) to the $1.8 \mathrm{ml}$ of solution in the storage chamber. This step was followed by Proteinase $\mathrm{K}\left(0.5 \mathrm{mg} \mathrm{m}^{-1}\right)$ digestion in the presence of $0.9 \%$ sodium dodecyl sulfate, phenol/chloroform/isoamyl alcohol extraction and ethanol precipitation. Several extraction blanks were included. Final DNA fractions were diluted to $5 \mathrm{ng} \mu \mathrm{l}^{-1}$ and $1 \mu \mathrm{l}$ was used in PCR with primer pair RTS1/RTS4. Extraction blanks were diluted to the same degree of dilution applied to the DNA fraction from the natural samples, in order to control for any inhibitory substances in these blanks.

GC-clamped amplicons for denaturing gradient and constant denaturant gel electrophoresis (DGGE/CDGE) analyses were obtained from RTS1/RTS4 amplicons by reamplification (starting with $2 \mu \mathrm{l}$ of a 200 -fold dilution of the PCR products in a total reaction volume of $25 \mu \mathrm{l}$ ) with the same primer pair except that RTS1 had a 40 bp GC 'clamp' added at the 5'-end (Myers et al 
1989, Murray et al. 1996). GC-RTS1 (65 bases) had the following sequence, with the 'clamp' being to the left of the slash: 5'-CGCCCGCCGCGCCCCGCGCCCGTCCCGCCGCCCCCGCCCC/TGATTTTATTGTTTAGTGAGAATGA-3'.

DNA sequencing. Double-stranded PCR products (generated with primers RTS1 and RTS4) were purified with carboxylated magnetic beads (DeAngelis et al. 1995) or on silica matrix filters (QIAquick PCR purification kit, QIAGEN, Valencia, CA, USA) prior to the cycle sequencing reaction. Cycling parameters applied to $30-40 \mathrm{ng}$ of amplicon for 50 cycles were: denaturation, $96^{\circ} \mathrm{C}, 10 \mathrm{~s}$; annealing, $66^{\circ} \mathrm{C}$ (found to be optimal for sequence quality), $5 \mathrm{~s}$; extension, $60^{\circ} \mathrm{C}, 4 \mathrm{~min}$. The ABI Prism Ready Reaction dye-terminator cycle sequencing kit was used with half the recommended volume (AmpliTaq DNA polymerase FS, PE Applied Biosystems, Foster City, CA, USA). These amplification conditions (volume, molar quantity of template and cycle number) led to $99.7 \%$ accuracy of base identification with plasmid pGEM3Z(f+) and the forward -21 M13 primer, the sequencing control included in the dye-terminator kit. Similar accuracies were seen under these conditions with a PCR product that had been exhaustively sequenced ( $R$. Zebell \& C.O. unpubl.).

An ABI PRISM model 377 DNA sequencer (PE Applied Biosystems) was used with DNA Sequence Analysis software version 2.1.2 for electrophoresis and sequence display. Sequence alignment and editing were performed with Sequencher 3.0 software (Gene Codes Corporation, Ann Arbor, Michigan, USA). Manual editing of ambiguities in the sequences produced by the instrument was performed using the rules concerning peak height patterns obtained with AmpliTaq DNA polymerase FS dye-terminator sequencing (Parker et al. 1996). The first 60 to $70 \mathrm{bp}$ displayed by the pherograms (next to each sequencing primer) were not included in the analyses as they are subject to severe noise from dye-terminator 'clouds' (ABI Prism DNA Sequencing, Chemistry Guide, PE Applied Biosystems).

DGGE and CDGE. The 'melting temperatures' of representative PCR products were first obtained on a perpendicular denaturing gradient gel cast with a BioRad model 475 gradient former in $16 \mathrm{~cm}$ long plates, part of the DCode ${ }^{\mathrm{TM}}$ mutation detection device (BioRad, Hercules, CA, USA). The gel of 6\% 37.5:1 acrylamide/bis-acrylamide with a 10 to $40 \%$ urea-formamide gradient $(100 \%=40.0 \mathrm{ml}$ deionized formamide and $42.0 \mathrm{~g}$ urea added to $100 \mathrm{ml}$ ) was prepared from components in the DCode electrophoresis reagent kit for DGGE/CDGE as described by the manufacturer (Bio-Rad). One hundred $\mu$ l of the PCR product was layered evenly along the top of the gel, and electrophoresis was carried out at $165 \mathrm{~V}$ and $56^{\circ} \mathrm{C}$ for $3.5 \mathrm{~h}$. Subse- quent parallel DGGE runs were performed with a gradient of 22 to $25 \%$ denaturants. The CDGE format, defined at a $23.5 \%$ level of denaturants, became the method of choice for monitoring natural specimens.

Gels were stained with ethidium bromide $\left(2 \mu \mathrm{g} \mathrm{ml} \mathrm{m}^{-1}\right.$ in $1 \times$ TAE buffer) for $10 \mathrm{~min}$, followed by destaining for $10 \mathrm{~min}$ in $1 \times$ TAE. Migration patterns were revealed by UV-fluorescence, digitized with the Gel Doc ${ }^{\text {TM }} 1000$ system (Bio-Rad), and analyzed as well as optimized for contrast and brightness with the Multi-Analyst software provided with the system. Images were saved in JPEG format and then manipulated for contrast and brightness, labeled and printed in Adobe Photoshop ${ }^{2}$ 4.0. Theoretical melting curves based on sequences of amplicons were generated with the WinMelt software, PC-Windows (Bio-Rad).

Mimic PCR. The composite primers and the competitor fragments for the quantitative PCR were constructed using the PCR Mimic Construction kit by Clontech $^{\circledR}$ Laboratories (Palo Alto, California, USA). The sequence (provided by Clontech ${ }^{2}$ ) of the $574 \mathrm{bp}$ BamHI/ECoRI fragment of the v-erbB avian blastoma virus, from which competitor fragments are constructed, was consulted to choose positions for the $3^{\prime}$ ends of the composite primers. Individual composite primers were designed with the sequences of the Piscirickettsia salmonis primers RTS1, RTS2 and RTS4 at their $5^{\prime}$ ends (underlined below) and the appropriate sequences of the $v$-erbB template at their $3^{\prime}$ ends. Primers RTS1mimic 1 (5'-TGATTTTATTGTTTAGTGAGAATGACGCAAGTGAAATCTCCTCCG-3'), RTS2mimic 3 (5'-AAATAACCCTAAATTAATCAAGGATTTCATCTCCCTGTATAACA-3'), and RTS4mimic6 (5' - ATGCACTTATTCACTTGATCATAATTTGATTCTGGACCATGGC-3') were paired in the PCR as RTS1mimic1/RTS2mimic3 and RTS1mimic1/RTS4mimic6 to give amplicons from the v-erbB template of expected sizes $248 \mathrm{bp}(157 \mathrm{bp}$ longer than the RTS1/RTS2 P. salmonis amplicon) and $554 \mathrm{bp}$ (270 bp longer than the RTS1/RTS4 P. salmonis amplicon), respectively.

Amplification conditions in a total reaction volume of $50 \mu \mathrm{l}$ were as follows: $1 \times$ PCR buffer $(10 \mathrm{mM}$ Tris- $\mathrm{HCl}$ $[\mathrm{pH} 8.3], 50 \mathrm{mM} \mathrm{KCl}, 1.5 \mathrm{mM} \mathrm{MgCl}_{2}$, and $0.001 \%$ [wt/vol] gelatin [PE Applied Biosystems]), each of the 4 deoxynucleoside triphosphates at a concentration of $0.2 \mathrm{mM}$, each oligonucleotide primer at a concentration of $0.4 \mu \mathrm{M}, 0.5 \mathrm{ng}$ of template, and $0.04 \mathrm{U}$ of AmpliTaq DNA polymerase (PE Applied Biosystems) $\mu l^{-1}$. A hot start (D'Aquila et al. 1991) was used to impede formation of primer duplexes: a mixture containing both primers and the 4 deoxynucleoside triphosphates was added after the other components for the reaction had reached $85^{\circ} \mathrm{C}$. The following thermal cycling regime was then applied: 7 cycles of denaturation at $94^{\circ} \mathrm{C}$ for 
$45 \mathrm{~s}$, annealing at $50^{\circ} \mathrm{C}$ for $45 \mathrm{~s}$ and extension at $72^{\circ} \mathrm{C}$ for $90 \mathrm{~s}$ followed by 18 cycles with the annealing temperature increased to $60^{\circ} \mathrm{C}$ and thereafter by a final extension at $72^{\circ} \mathrm{C}$ for $7 \mathrm{~min}$. PCR products were visualized after electrophoresis in agarose gels (1.5\%). A portion of each desired product was removed with a pasteur pipette, transferred into $50 \mu \mathrm{l}$ of $1 \times$ LTE (10 mM Tris-HCl [pH 8.0], 0.1 mM EDTA) and eluted

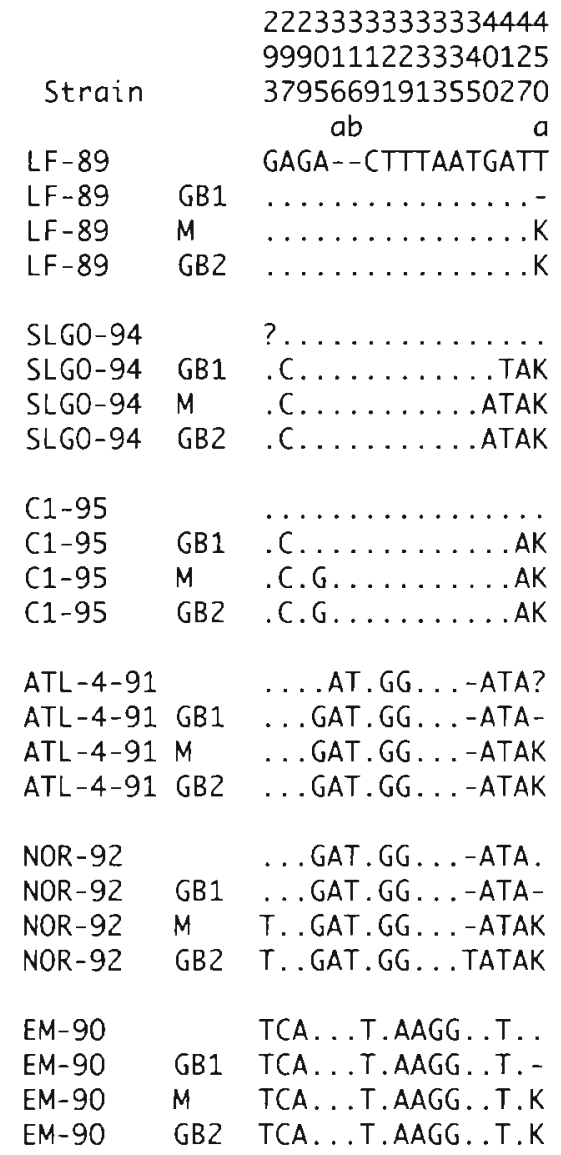

Fig. 1 Variation in the ITS region of the rRNA operon in reported Piscirickettsia salmonis strains. The polymorphic sites are listed vertically across the top, with their numbers corresponding to the LF-89 U36943.1 sequence in GenBank; lowercase letters denote sites added $3^{\prime}$ of the indicated nucleotide relative to this sequence. The sequence we determined for LF-89 is shown at all sites; the bases in the other sequences are shown only where different. -: deletions relative to other sequences $\mathrm{K}$ indicates $T$ or $G_{i}$ ?: unsequenced sites. GB1 to the right of the strain designation indicates GenBank 1995-1996 accessions of sequences (LF-89, U36943.1; SLGO-94, U62104.1; C1-95, U62103.1; ATL-4-91, U36945.1; NOR-92, U36946.1; EM-90, U36944.1), M denotes sequences shown in Mauel et al. (1999) and GB2 indicates sequences submitted to GenBank on January 19, 2000 (i.e., LF-89, U36943.2; SLGO-94, U62104.2, and so on). In the numbering of U36943.1, we sequenced, with no ambiguities, positions 224-458 (the entire segment between primers RTS1 and RTS4) for LF-89 and EM-90, 294-451 for SLGO-94, 252-457 for C1-95, 242-447 for ATL-4-91 and 245-455 for NOR-92 by incubation at $65^{\circ} \mathrm{C}$ for $1 \mathrm{~h}$. The eluates $(1 \mu \mathrm{l})$ served as templates for amplification (in a reaction volume of $50 \mu \mathrm{l})$ with the corresponding Piscirickettsia salmonisspecific primer pairs, i.e., RTS1/RTS4 and RTS1/RTS2, to reach concentrations suitable for subsequent competitive PCR experiments. Each primer was present at a concentration of $0.25 \mu \mathrm{M}$, the polymerase at $0.03 \mathrm{U}$ $\mu^{-1}$, and the buffer and dNTPs at the concentrations given above. The cycling regime was as detailed above except that 16 (not 18) cycles with an annealing temperature of $55^{\circ} \mathrm{C}$ (not $60^{\circ} \mathrm{C}$ ) were included. Amplicons were purified on MagBeads (DeAngelis et al. 1995) and stored and diluted in $1 \times$ LTE containing $10 \mu \mathrm{g}$ of ultrapure glycogen $\mathrm{ml}^{-1}$ to prevent adhesion of nucleic acids to plastic surfaces. After electrophoresis through $1.5 \%$ agarose, quantification of the Mimic fragments was done by densitometry of stained gels using the Bio-Rad Gel Doc ${ }^{\text {TM }} 1000$ system set to show saturated pixels so as to ensure that detection remained in the linear range for adequate quantification. Special attention was given to accuracy of micropipetting and prevention of cross-contamination for competitive PCR measurements. Co-amplification of P. salmonis plus Mimic templates was carried out in $12.5 \mu \mathrm{l}$ volumes with the PCR protocol described by Marshall et al. (1998).

Quantitative estimation of Piscirickettsia salmonis with the competitive PCR method was used also to evaluate the representation of bacterial sequences in a DNA extract from $P$. salmonis EM-90 propagated in chinook salmon Oncorhynchus tshawytscha embryo cell line CHSE-214 (Lannan et al. 1984, Marshall et al. 1998). In an attempt to reduce appreciably contributions of host DNA, the extraction was performed from a cell culture exhibiting full cytopathic effect that had been treated with DNAseI followed by washes and differential centrifugation before lysis of the bacterial cells, as outlined previously (Marshall et al. 1998).

\section{RESULTS}

\section{Sequencing of the ITS from reported Piscirickettsia salmonis strains}

An earlier discrepancy (Marshall et al. 1998) with the reported sequence of a section of the ITS locus of Piscirickettsia salmonis LF-89 prompted us to examine the ITS sequence of the other reported strains of $P$. salmonis, as noted in a preliminary account (Heath et al. 1999). We found in all $P$. salmonis strains except ATL4-91 (unsequenced near primer RTS4) an extra $T$ in the run of 4 Ts reported in GenBank accession U36943.1 as present in LF-89 at positions 448 to 451 (Fig. 1). A recent publication (Mauel et al. 1999) and updated 
Table 1. Pairwise sequence differences in the ITS region among Piscirickettsia salmonis strains. Above the diagonal are the observed nucleotide substitutions, exclusive of insertions and deletions, among the sequences determined in the present study (Fig. 1). Below the diagonal are the percent sequence differences for 202 nucleotides compared among all 4 strains listed here (Fig. 1). LF-89 represents also the identical sequences found for SLGO-94 and C1-95

\begin{tabular}{|lcccc|}
\hline Strain & LF-89 & ATL-4-91 & NOR-92 & EM-90 \\
\hline LF-89 & & 5 & 6 & 9 \\
ATL-4-91 & 2.5 & & 1 & 11 \\
NOR-92 & 3.0 & 0.5 & & 12 \\
EM-90 & 4.5 & 5.4 & 5.9 & \\
\hline
\end{tabular}

sequences submitted to GenBank in 2000 showed a K at $450 \mathrm{a}$ for all 6 strains plus 3 or 4 other differences within the segment bounded by RTS1 and RTS4 relative to the sequences Mauel and colleagues submitted to GenBank in 1995 and 1996 (Fig. 1). We noted additional differences from all the hitherto reported sequences (Fig. 1), such that fragments flanked by primer binding sites RTS1 and RTS4 were reduced from 6 to 4 sequence types (Fig. 1, Table 1), including 1 type common to Chilean isolates LF-89, SLGO-94 and C1-95 and also to $P$. salmonis sequenced from 2 Chilean rainbow trout by Marshall et al. (1998). GenBank accession numbers are AF212834 to AF212839 for the sequences we determined from the 6 reported $P$. salmonis strains and AF212840 to AF212841 for the $P$. salmonis sequences from the 2 additional Chilean fish. For a length of 236 to $237 \mathrm{bp}$, we detected 16 polymorphic sites among our own sequences (Fig. 1). Pairwise nucleotide substitutions among our sequences range from 0.5 to $5.9 \%$ (Table 1 ).

\section{Denaturant gel electrophoresis assessment of Piscirickettsia salmonis variation}

An initial examination of the melting properties of the RTS1/RTS4 fragment was conducted with amplicons generated from one of the most distantly related pairs, LF-89 and EM-90 (Table 1). A perpendicular DGGE analysis at $56^{\circ} \mathrm{C}$ revealed 2 melting transitions, at inflection points of 24 and $27 \%$ denaturant concentration (Heath et al. 1999). The theoretical melting curves for the 2 sequences had 2 melting domains, one at $62^{\circ} \mathrm{C}$ and a second between 62 and $63.5^{\circ} \mathrm{C}$ (Heath et al. 1999). Therefore, the experiment and melting theory (Lerman \& Silverstein 1987) roughly agree, as the differential in the observed inflection points corresponds to $0.3^{\circ} \mathrm{C} / 1 \%$ denaturant (Abrams \& Stanton 1992). The prediction of higher melting values for EM90 compared to LF-89 was confirmed in the parallel

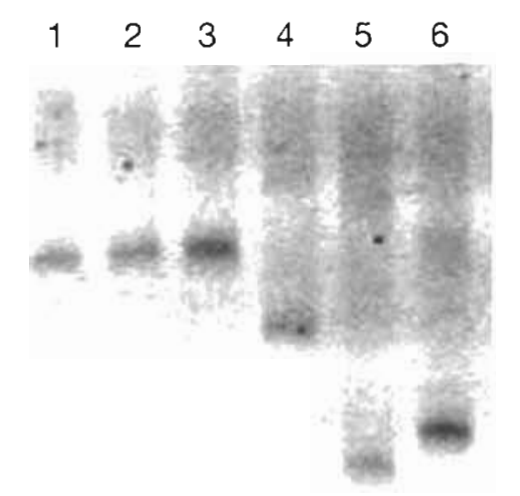

Fig. 2. CDGE of GC-RTS1/RTS4 amplicons from Piscirickettsia salmonis strains C1-95 (lane 1), SLGO-94 (lane 2), LF-89 (lane 3), ATL-4-91 (lane 4), EM-90 (lane 5) and NOR-92 (lane 6). Electrophoresis was carried out in a $4 \%$ polyacrylamide gel with $23.5 \%$ denaturants at $130 \mathrm{~V}$ and $56^{\circ} \mathrm{C}$ for $3 \mathrm{~h} 15 \mathrm{~min}$

DGGE format with a gradient ranging between 20 and $25 \%$ (results not shown) and also by CDGE (Fig. 2).

Adequate separation of the Piscirickettsia salmonis sequence types depended on a narrow denaturant gradient and therefore was susceptible to the vagaries of gradient casting, particularly at the beginning of the gradient, which would influence relative migration patterns and make comparisons between runs more challenging. A constant denaturant concentration of $23.5 \%$ and a $4 \%$ polyacrylamide gel gave the best separation among the sequence variants (Fig. 2). CDGE became the preferred format given the likelihood of higher reproducibility because gels are cast at a single urea-formamide concentration. Four migration classes clearly emerged: EM-90 > NOR-92 > ATL-4-91 > LF-89 = C1-95 = SLGO-94 (Fig. 2). Clustering of the last 3 agrees with our sequence data (Fig, 1). Artificial mixtures of sequence types ATL-4-91 and LF-89 were used as markers and also as a test of the technical quality of the run in subsequent assessments via CDGE (Fig. 3, lanes 1, 8 and 14). Fragments that differed by 1 substitution (Table 1) were clearly distinguished in the case of ATL-4-91 and NOR-92 (Fig. 2, lanes 4 and 6). As is evident from Fig. 2 and Table 1, the degree of difference in migration in DGGE and CDGE is not proportional to the degree of sequence difference because the least stable part of the molecule is largely responsible for retardation during migration under denaturing conditions, with other parts of the sequence and the overall length of the fragment having little influence on retardation (Fischer \& Lerman 1983). Thus the nature and location of sequence differences, rather than their number, will determine the relative mobilities of variants. It should be pointed out, furthermore, that all polymorphic sites reported (from positions 293 to 450a; see Fig. 1) fall into a section that extends from 


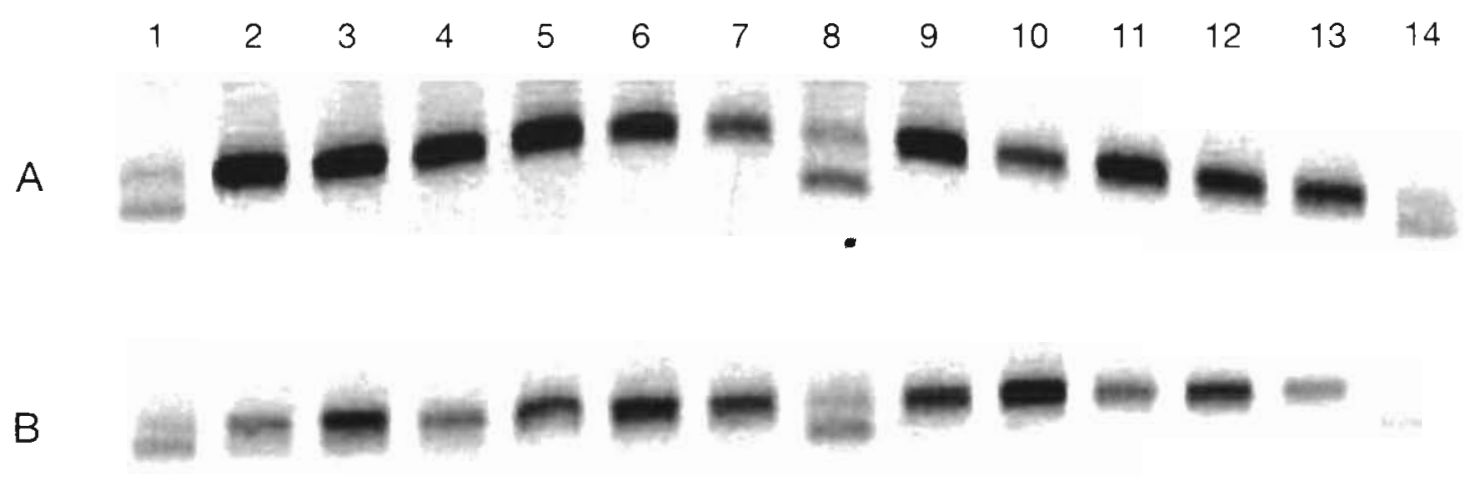

Fig. 3. CDGE of Piscirickettsia salmonis fragments amplified with primer pair RTS1/RTS4 from samples obtained at fish farms in southern Chile. Groups are described in Table 2. A standard mixture of amplicons from ATL-4-91 (more rapidly migrating band) and LF-89 is in lanes 1, 8 and 14 in both panels. (A) Group 1 (lanes 2-6), Group 8 (lane 7), Group 2 (lanes 9-13). (B) Group 2 (lanes 2-4), Group 4 (lanes 5-7 and 9-13). The gel was $4 \%$ polyacrylamide with $23.5 \%$ denaturants and was run at $130 \mathrm{~V}$ for 2 h $40 \mathrm{~min}$ at $56^{\circ} \mathrm{C}$

base 135 of the GC-clamped PCR fragment to its end, well within the first melting domain predicted by theory (Heath et al. 1999).

Screening of Piscirickettsia salmonis extracted from coho salmon (38 individuals) and rainbow trout (6 individuals) from farms in the south of Chile during the 1997 and 1998 seasons by CDGE (Fig. 3, Table 2) implied that 1 sequence type, LF-89-like, was common to all 44 samples from tissue biopsies obtained from 5 (or 6) different salmon farms on and near Chiloé Island.

\section{Quantitative PCR: validation and application for Piscirickettsia salmonis}

Assessment of the efficiency of amplification of the competitor fragments synthesized for quantitative PCR by serial dilution experiments showed that both the RTS1/RTS2 and the RTS1/RTS4 Mimic fragments could be amplified from as little as approximately a single copy of template (lane 8 of Fig. 4; Heath 1999).
Reamplification of the genuine RTS1/RTS2 and RTS1/ RTS4 fragments from Piscirickettsia salmonis LF-89 was equally efficient (Heath 1999). In addition, coamplification of equal numbers of copies through a representative range of 10 -fold dilutions of RTS1/RTS2 and its Mimic fragment also manifested similar efficiencies for both fragments in all instances (Heath 1999). The accuracy of quantification using controlled target numbers was assessed by submitting 100 copies of the $P$. salmonis RTS1/RTS2 fragment to quantitative PCR with a dilution series of its Mimic fragment. After allowing for a 2.7 -fold factor in fluorescent signal intensity (248 bp Mimic fragment/91 bp $P$. salmonis fragment), the competitive measurement predicted close to 100 copies for the fragment in question (lane 5 in Fig. 4).

The effect of DNA strand length on quantification was also assessed. Evaluation of copy number from genomic templates raises questions of possibly unequal influences on amplification efficiencies (of genomic vs Mimic sequences) due to the dynamics of sep-

Table 2. Salmonids surveyed for Piscirickettsia salmonis by PCR and CDGE. Fish farm locations are on and adjacent to Chiloé Island $\mathrm{CS}=$ coho salmon and $\mathrm{rt}=$ rainbow trout; water refers to the life cycle stage when the specimen was obtained. For the tissue column of Groups 5, 6 and $8, K=$ kidney, $\mathrm{L}=$ liver and $\mathrm{B}=$ brain. The unknown location may be 1 of the $5 \mathrm{known}$ sites listed

\begin{tabular}{|c|c|c|c|c|c|c|c|}
\hline Group & Location & Date & Salmonid & Number & Water & Tissue(s) & Type (no.) \\
\hline 1 & Unknown & Jul 1997 & Adult cs & 8 & Salt & Kidney & LF-89(8) \\
\hline 2 & Caucahué & Jul 1997 & Adult cs & 9 & Salt & Kidney & LF-89 (9) \\
\hline 3 & Compu & Jul 1997 & Adult rt & 1 & Salt & Kidney & LF-89 (1) \\
\hline 4 & Puerto Montt & Oct 1997 & Adult cs & 9 & Salt & Kidney & LF-89 (9) \\
\hline 5 & Quemchi & Oct 1997 & Adult rt & 3 & Salt & $2 \mathrm{~K}, 1 \mathrm{~L}$ & LF-89 (3) \\
\hline 6 & Quemchi & Oct 1997 & Adult CS & 4 & Salt & $1 \mathrm{~K}, 3 \mathrm{~L}$ & LF-89 (4) \\
\hline 7 & Potemún & Oct 1997 & Smolt cs & 2 & Fresh & Liver & LF -89 (2) \\
\hline 8 & Potemún & Oct 1997 & Smolt rt & 2 & Fresh & $1 \mathrm{~B}, 1 \mathrm{~L}$ & LF-89 (2) \\
\hline 9 & Caucahué & Nov 1998 & Adult cs & 6 & Salt & Kidney & LF-89 (6) \\
\hline
\end{tabular}




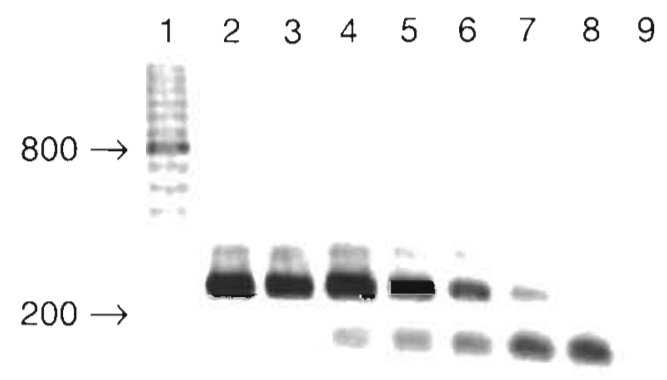

Fig. 4. Quantification by competitive PCR of 100 copies of Piscinickettsia salmonis RTS1/RTS2 amplicon $(91 \mathrm{bp})$ with RTS1/RTS2 Mimic fragment (248 bp). Lanes 2-8 show the products obtained in competitive PCR starting from 100 copies of the $P$. salmonis RTS1/RTS2 amplicon plus - going from lane 2 to lane $8-10000,1000,500,100,50,10$ and 1 copies of the RTS1/RTS2 Mimic fragment. A negative PCR control is in lane 9 . Lane 1 contained a 100 bp ladder with the $800 \mathrm{bp}$ fragment intensified; sizes (in base pairs) are indicated on the left

aration of strands of variable lengths (as in genomic template extracts) and the efficiencies of priming at higher sequence complexity (as contributed by the Piscirickettsia salmonis template and even more so by the genome of the salmonid host). We took advantage of 2 $R$ saI restriction sites flanking the ITS locus in LF-89, at positions 6 and 666 in GenBank accession U36943.1. The primer sites ( $3^{\prime}$ ends) for RTS1 and RTS2 are at positions 223 and 266, respectively. A Mimic experiment was done with non-digested $P$. salmonis LF-89 DNA (extracted with organic solvents) as well as with LF-89 DNA digested with RsaI. A parallel digestion of $1 \mu \mathrm{g}$ of lambda DNA mixed with the $P$. salmonis template under the same buffer conditions as the Mimic PCR experiment served as a control for Rsal activity (10 $\mathrm{U}$ of enzyme $\mathrm{\mu g}^{-1}$ DNA). The restriction enzyme was inactivated during the first denaturation step of the PCR. Approximately 1000 copies of the $P$. salmonis genome (assuming 1 rRNA operon per genome; see Mauel et al. 1999) were measured whether or not genomic DNA was digested before serving in the competitive amplification. It was also shown that quantification of the same kidney-derived Chelex DNA prepa- ration on different days (with a 10-fold dilution series of the Mimic fragment) was reproducible to well within an order of magnitude (Heath 1999).

Comparison of initial Piscirickettsia salmonis template number in brain and liver samples from an adult coho salmon collected from the Caucahue Channel in November 1998 indicated that the infection load was higher in brain tissue than in the liver biopsy by 2 orders of magnitude (Fig. 5). The number of genome copies estimated for the liver specimen was approximately 5 (Fig. 5B), while in the analysis of another infected adult coho salmon, kidney and liver had 10 copies (results not shown).

Spectrophotometric measurement showed that total DNA yields in extracts of ocean water samples collected via Sterivex filtration were between 5 and $8 \mu \mathrm{gg}$ sample ${ }^{-1}$ (ratio of optical densities $\mathrm{OD}_{260 / 280}>1.7$ ), and analysis by electrophoresis in $0.7 \%$ agarose gels confirmed that $>90 \%$ of the nucleic acid was in a fraction above $23000 \mathrm{bp}$ in length. Quantification of the DNA fraction obtained from water collected at the surface of an active netpen displaying a fish mortality of $2.1 \%$ $\mathrm{wk}^{-1}$ (background mortality, $0.3 \% \mathrm{wk}^{-1}$ ) indicated the presence of approximately 10 Piscirickettsia salmonis genome copies in the concentrated sample used for the Mimic PCR, which extrapolated to 3440 copies $\mathrm{l}^{-1}$ of seawater in the netpen. (This value may be an underestimate, as some bacteria are expected to be held back during prefiltration on the GF/A filter.) A surface sample collected approximately $600 \mathrm{~m}$ away from the pen was negative in the PCR.

Competitive PCR applied to an extract of Piscirickettsia salmonis EM-90 made after appreciable reduction of the content of host DNA (i.e., chinook salmon DNA from cell line CHSE-214) revealed 1000 copies of the $P$. salmonis chromosome in $10 \mathrm{ng}$ of purified DNA. Assuming the $P$. salmonis genome is about $4 \times 10^{6}$ bp long (Escherichia coli, also a member of the gamma subgroup of proteobacteria, has a genome of $4.7 \times 10^{6}$ $\mathrm{bp}$ ), this translates into $0.04 \%$ of the nucleic acid material consisting of DNA sequence from the microorganism, with the rest necessarily made up of host cell DNA. (Heath 1999).

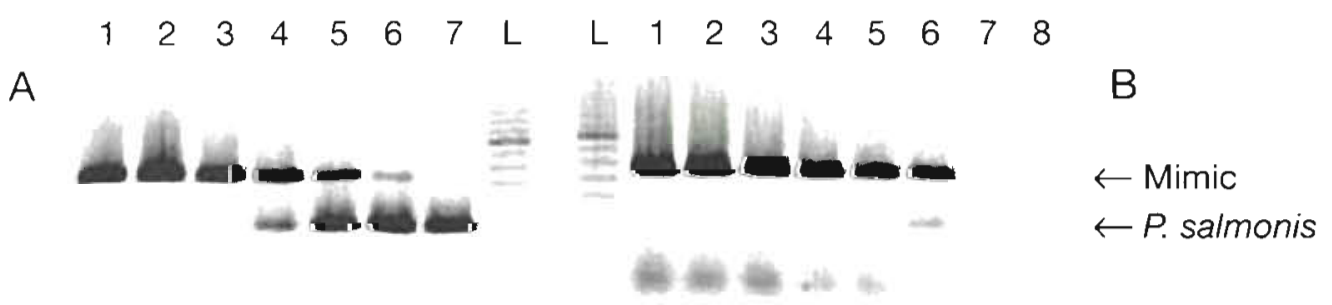

Fig. 5. Quantitative PCR with primer pair RTS1/RTS4 and DNA from (A) brain and (B) liver biopsies of an adult coho salmon with piscirickettsiosis. Chelex-extracted salmon DNA $(1 \mu$ l, lanes $1-7)$ was amplified along with $10^{6}, 10^{5}, 10^{4}, 10^{3}, 10^{2}, 10^{1}$ and $10^{0}$ copies (lanes 1-7, respectively) of RTS1/RTS4 Mimic fragment (554 bp). Lane 8 (B) was a negative control with no DNA added. $\mathrm{L}$ contains the 100 bp ladder described in Fig. 4 


\section{DISCUSSION}

\section{Assessment of genetic variation of Piscirickettsia salmonis via the ITS}

The ITS section of the rRNA operon is often considered the most promising locus for exploring intraspecific distinctions among prokaryotes (for a recent review, see Mauel et al. 1999), though this approach is complicated when the organism harbors more than 1 rRNA operon. Escherichia coli has 7 such operons, with 3 containing 2 tRNA genes within their ITS region and the other 4 operons containing 1 tRNA gene different from the former 2 (Condon et al. 1995). Examples of 3 different versions of the ITS within a cell, with different numbers of tRNA insertions $(3,2$ and 1$)$ in the spacer, have been reported in the genus Vibrio (Chun et al. 1999). Mauel et al. (1999) have postulated, based on their cloning studies, the existence of only 1 ITS copy per genome for each of the reported Piscirickettsia salmonis isolates studied here. A detailed analysis of percent sequence identity is now available for 3 genetic regions of the rRNA operon in $P$. salmonis (Mauel et al. 1999). With only 1 exception (ATL-4-91 vs NOR-92), the ITS (309 nucleotide positions not including ambiguous positions) displayed at least as much variation as the $16 \mathrm{~S}$ and $23 \mathrm{~S}$ rRNA genes (Mauel et al. 1999). Therefore, focusing on the ITS appears justified for future surveys of genetic variation of $P$. salmonis that might alert us to the emergence of new genetic lineages of the organism in the habitats of southern Chile. The sequence discrepancies summarized in Fig. 1 do not detract from the argument that ITS is a suitable locus for such appraisals. More global assessments of the $P$. salmonis genome for genetic variation - for example by genomic fingerprinting using arbitrarily primed PCR (Welsh \& McClelland 1993) are not yet possible given the considerable obstacles in purifying the microorganism from cellular debris, including nucleic acids of its host (Barnes et al. 1998, S.M. unpubl.). Such purification is a prerequisite also for the establishment of future genome libraries representative of this intracellular pathogen.

Integration of the current studies (1997 and 1998 seasons) with an earlier one (1996 and 1997 seasons: Marshall et al. 1998) points to homogeneity of genetic types in Piscirickettsia salmonis obtained from coho salmon and rainbow trout from southern Chile, whether at their freshwater or salt water life stages (Fig. 3, Table 2). Earlier isolates SLGO-94 (rainbow trout) and C1-95 (coho salmon) also share an identical ITS sequence with LF-89, according to our studies (Fig. 1). Therefore, in the decade since the piscirickettsiosis syndrome was described (Bravo \& Campos 1989) and $P$. salmonis strain LF-89 isolated (Fryer et al.
1990. Cvitanich et al. 1991) and typed (Fryer et al. 1992), this particular lineage has dominated the epidemiology of the disease throughout the huge expansion of the salmon farming industry in Chile. Intense habitat adaptation by $P$. salmonis might be involved. The 3 geographic isolates - LF-89 (Chile), ATL-4-91 (British Columbia, Canada) and NOR-92 (Norway) which also comprise distinct phylogenetic isolates (Heath 1999, Mauel et al. 1999), display different degrees of virulence in controlled infections, with LF89 being the most virulent (House et al. 1999). This picture is compatible with Chile being the site of highest incidence and prevalence of piscirickettsiosis.

Future epidemiological surveys by, for example, the CDGE protocol presented here (Fig. 3) might alter this view of the apparent constancy of genetic lineage of the Piscirickettsia salmonis pathogen in the Chilean salmon industry. (Preliminary reports [S. Valdebenito \& B. Jauriguiberry pers. comm. from 1995 mentioned by Olsen et al. 1997. Casanova et al. 1999] have suggested that 1 to 3 additional variants of $P$. salmonis, beyond LF-89-like and EM-90, may occur among Chilean salmonids.) To date we have obtained DNA sequences for only 2 recent Chilean specimens, and they were identical to our LF-89 sequence (Marshall et al. 1998). Surveys reveal that mutation detection via DGGE is highly comprehensive (>95\%; see Cotton 1997) when performed with GC-clamped fragments, provided that primers are positioned such that mutations internal to the primers occur in the first melting domain as predicted by first principles (Lerman \& Silverstein 1987) and computational simulations. Therefore, new variants in the ITS region of $P$. salmonis are likely to be evident in the future via CDGE, if their sequence changes continue to occur in the section corresponding to the lowest ranking melting domain of the amplified fragment.

A number of studies have illustrated the power of denaturant gel electrophoresis to distinguish even transversions leading to the interchange of bases across strands, as would be the case for $\mathrm{G}-\mathrm{C}$ and A-T transversions (Fischer \& Lerman 1983, Ridanpää et al. 1995. Hepburn \& Miller 1998). Judicious PCR primer positioning can lead to detection of all transversions of the type discussed here without resorting to the more elaborate analysis of heteroduplexed entities (Hepburn \& Miller 1998). Therefore, there are grounds for confidence that the paucity of types as revealed by CDGE is the manifestation of sequences identical to LF-89 for the ITS region we studied. The suggestion that the same LF-89like lineage of Piscirickettsia salmonis seems to have prevailed since the dawn of the salmon industry in Chile in 1982 to the present has reassuring implications in regard to the dependability of future vaccines against $P$. salmnonis for coho salmon and rainbow trout. 


\section{The quantitative approach for the understanding of Piscirickettsia salmonis}

Competitive PCR with the Piscirickettsia salmonis system offers a robust approach for the quantitative measurement of genome copy number of the microorganism. Results appeared to be reproducible despite different storage times and features of template quality that are otherwise hard to control, such as template lengths of genomic preparations. Confidence of measurement was well within an order of magnitude (for example, Fig. 4). Competitive PCR also allowed us to estimate the sensitivity of the current PCR assay: detection of approximately 1 to 10 P. salmonis genome equivalents is possible against a large background $(>99 \%$ ) of the salmonid DNA (for example, Fig. 5). Though simple in execution and reagents, compared to more automated and costly approaches to quantitative PCR via real-time or kinetic amplification protocols (Higuchi \& Watson 1999), competitive PCR as described here is demanding in regard to accuracy of pipetting and avoidance of cross-contamination.

Obtaining precise numbers of Piscirickettsia salmonis genomes at different anatomical sites of infection should shed new light on the routes of invasion of the pathogen. The almost indiscriminate systemic invasion of $P$. salmonis has been well documented. In addition to characteristic lesions in the liver, kidney and spleen, the intestine, brain, skeletal muscle, heart and skin as well as macrophages have all been implicated (see Almendras \& Fuentealba 1997). Nevertheless, it was surprising to discover that in one case the estimated number of resident $P$. salmonis cells in biopsies of $<0.25 \mathrm{mg}$ was 100 times higher in the brain compared to liver (Fig. 5). These observations raise the possibility of lower bacterial loads in tissues considered to be primary foci of invasion, compared to the brain, and suggest that this organ might be a preferred site of $P$. salmonis infection. They also point to the need for large-scale quantitative surveys of bacterial burdens in the brain and a variety of other tissues within individual fish. Non-PCR technology for quantifying the number of $P$. salmonis cells accurately in a routine fashion, even using antibodies (as in the fluorescent antibody test), is notoriously inadequate. These complications reflect the fact that this organism is an intracellular pathogen that cannot yet be grown in pure culture. We have endeavored to standardize tissue weights to a reasonable extent by taking biopsies of the same size. Furthermore, the nature of the Mimic PCR approach controls for differential efficiencies of amplification to be expected from different tissues or extracts.

A conservative calculation (1 ng for the weight of a eukaryotic cell) leads to bacterial loads of about 1 Piscirickettsia salmonis per 5 brain cells of the fish in the case we studied. Of course, our measurements could mean, for example, that only 1 of every 50 fish brain cells is infected, with each infected cell carrying a burden of 10 bacterial organisms. Phase contrast microscopy on P. salmonis-infected CHSE-214 cells suggests that at 2 to $3 \mathrm{~d}$ post inoculation such loads per cell are possible; counting of $P$. salmonis particles within membrane-bound cytoplasmic vacuoles reveals at least 18 organisms per vacuole in one case (Fryer et al. 1992) and in the other a minimum of 8 per vacuole (Garcés et al. 1991). Similar burdens are clearly visible by transmission electron microscopy of an infected hepatocyte in Salmo salar (Olsen et al. 1997).

Competitive PCR should also be helpful in the elucidation of ecological scenarios in the transmission of Piscirickettsia salmonis leading to natural outbreaks. Its detection and quantification in seawater from a netpen at a density of 3440 cell equivalents $\mathrm{l}^{-1}$ add to earlier evidence for possible horizontal transmission via seawater (Cvitanich et al. 1991, Lannan \& Fryer 1994, Almendras et al. 1997). Other avenues of transmission (see Almendras \& Fuentealba 1997, Olsen et al. 1997), such as by coprophagy, via algal blooms and zooplankton (particularly copepods) and by an external hematophagous isopod parasite of salmonids (Garcés et al. 1994), could be better evaluated with quantitative appraisals of bacterial loads. Certification of ova and of sites for salmon cultivation following fallow periods (Cassigoli 1994) could also benefit from the quantitative approach

It is conceivable that amplification of DNA or even rRNA might result in false pictures, as positive signals from such targets can be obtained from nonviable bacteria (see Sheridan et al. 1998, Cook \& Lynch 1999) and bacterial cell debris (Dupray et al. 1997). Reverse transcription (RT) PCR to detect bacterial messenger (m) RNAs of short half lives is increasingly being employed to monitor for the presence of viable bacteria (Sheridan et al. 1998, Cook \& Lynch 1999). Competitive PCR can be implemented as part of RT-PCR (Gilliland et al. 1990). However, awareness of a viable but nonculturable state that bacteria enter upon exposure to low nutrient conditions (Steinert et al. 1997), without loss of $16 \mathrm{~S}$ rRNA and presumably with drops in mRNA, should temper decisions to exclude DNA-based PCR assays in favor of the RT-PCR mode in evaluations of microorganisms in natural habitats.

\section{Molecular approaches in the management of disease in aquaculture}

Simplifications to the methodology presented here are conceivable, so as to permit more practical contributions of the molecular approach to disease manage- 
ment in aquaculture of salmonids. The CDGE format is amenable to preparation of pre-cast gels in large quantities (for subsequent long-term storage). The use of fluorescent-labeled primers would eliminate staining with ethidium bromide after the electrophoresis run. For the Mimic procedure, microtiter plates with wells previously loaded with dilution series of the Mimic fragment and dehydrated for storage can be used. Pre-casting gels and delivering nucleic acids in a dehydrated state for their quantitative recovery in biochemical reactions are already practiced in today's biotechnology commerce. Their application to aquaculture management appears as a desirable and practical goal.

Acknowledgements. This work received support from Minority Biomedical Research Support grant GM52588 from the National Institutes of Health; the Dirección de Investigación y Postgrado, Universidad Católica de Valparaíso; Fomento al Desarrollo Científico y Tecnológico/Comisión Nacional de Investigación Científica y Tecnológica project 1038; and (for partial support of C.O.) National Science Foundation grant OCE-9315639 to J. T. Hollibaugh, San Francisco State University. We thank V. Henriquez and A. M. Skármeta for salmonid samples; M. J. Mauel for DNA samples of Piscirickettsia salmonis strains; A. E. Murray, P. S. Wong and B. Temesgen for technical advice; $P$. Owings for sequencing help; A. Patel for the WinMelt program; D. H. De Vaughn. BIO PLAS Inc., for donations of plastic supplies; and V. Henríquez for discussion. This work was in partial fulfillment of a Master of Arts degree by S.H.

\section{LITERATURE CITED}

Abrams ES, Stanton VP (1992) Use of denaturing gradient gel electrophoresis to study conformational transitions in nucleic acids. Methods Enzymol 212:71-104

Almendras FE. Fuentealba IC (1997) Salmonid rickettsial septicemia caused by Piscirickettsia salmonis: a review. Dis Aquat Org 29:137-144

Almendras FE, Fuentealba IC, Jones SRM, Markham F, Spangler E (1997) Experimental infection and horizontal transmission of Piscirickettsia salmonis in freshwater-raised Atlantic salmon, Salmo salar L. J Fish Dis 20:409-418

Barnes MN, Landolt ML, Powell DB, Winton JR (1998) Purification of Piscirickettsia salmonis and partial characterization of antigens. Dis Aquat Org 33:33-41

Bravo S, Campos M (1989) Coho salmon syndrome in Chile Am Fish Soc Health Sec Newsl. 17(3):3

Casanova A, Obreque J, Jadue C, Paez M, Jashés M (1999) Estudio de la región espaciadora 16S-23S (ITS) de Piscirickettsia salmonis. XXI Congreso Chileno de Microbiología. October 9-12, Valdivia, Chile, Abstract 8, p 23-24

Cassigoli J (1994) Septicemia rickettsial del salmón. In: Fundación Chile (ed) Proceedings Primer Seminario Internacional: Patología y nutrición en el desarrollo de lá acuicultura: factores de éxito. October 3-7, Puerto Montt, Chile, p $17-20$

Chun J, Huq A, Colwell RR (1999) Analysis of 16S-23S rRNA intergenic spacer regions of Vibrio cholerae and Vibrio mimicus. Appl Environ Microbiol 65:2202-2208
Condon C, Squires C, Squires CL (1995) Control of IRNA transcription in Escherichia coli. Microbiol Rev 59: $623-645$

Cook M, Lynch WH (1999) A sensitive nested reverse transcriptase PCR assay to detect viable cells of the fish pathogen Renibacterium salmoninarum in Atlantic salmon (Salmo salar L.). Appl Environ Microbiol 65:3042-3047

Cotton RGH (1997) Mutation detection. Oxford University Press, Oxford

Cvitanich JD, Gárate ON, Smith CE (1991) The isolation of a rickettsia-like organism causing disease and mortality in Chilean salmonids and its confirmation by Koch's postulate. J Fish Dis 1.4:121-145

Cvitanich JD, Gárate O, Silva C, Andrade M, Figueroa C, Smith CE (1995) Isolation of a new rickettsia-like organism from Atlantic salmon in Chile. Am Fish Soc Health Sec Newsl 23(3):1-3

D'Aquila RT, Bechtel LJ, Videler JA, Eron JJ, Gorczyca P, Kaplan JC (1991) Maximizing sensitivity and specificity of PCR by pre-amplification heating. Nucleic Acids Res 19: 3749

DeAngelis MM, Wang DG, Hawkins TL (1995) Solid-phase reversible immobilization for the isolation of PCR products. Nucleic Acids Res 23:4742-4743

Dupray E, Caprais MP, Derrien A, Fach P (1997) Salmonella DNA persistence in natural seawaters using PCR analysis. J Appl Microbiol 82:507-510

Fischer SG, Lerman LS (1983) DNA fragments differing by single base-pair substitutions are separated in denaturing gradient gels: correspondence with melting theory. Proc Natl Acad Sci USA 80:1579-1583

Fryer JL, Lannan CN (1996) Rickettsial infections of fish. Annu Rev Fish Dis 6:3-13

Fryer JL, Mauel MJ (1997) The rickettsia: an emerging group of pathogens in fish. Emerg Infect Dis 3:137-144

Fryer JL, Lannan CN, Garcés LH, Larenas JJ, Smith PA (1990) Isolation of a rickettsiales-like organism from diseased coho salmon (Oncorhynchus kisutch) in Chile. Fish Pathol $25: 107-114$

Fryer JL, Lannan CN, Giovannoni SJ, Wood ND (1992) Piscirickettsia salmonis gen. nov., sp. nov., the causative agent of an epizootic disease in salmonid fishes. Int J Syst Bacteriol 42:120-126

Garcés LH, Larenas JJ, Smith PA, Sandino S, Lannan CN, Fryer JL (1991) Infectivity of a rickettsia isolated from coho salmon Oncorhynchus kisutch. Dis Aquat Org 11:93-97

Garcés LH, Correa P, Larenas J, Contreras J, Oyanadel S, Fryer JL, Smith-Shuster PA (1994) Finding of Piscirickettsia salmonis in Ceratothoa gaudichaudii. International Symposium on Aquatic Animal Health. September 4-8, Seattle, WA, Abstract, P-109

Gilliland G, Perrin S, Bunn HF (1990) Quantitative PCR for quantification of mRNA. In: Innis MA, Gelfand DH, Sninsky JJ, White TJ (eds) PCR protocols. A guide to methods and applications. Academic Press, San Diego, p 60-69

Heath S (1999) Molecular diagnosis and ecology of Piscirickettsia salmonis: a bacterial pathogen of salmonids. Master's thesis, San Francisco State University, San Francisco, CA

Heath S, Pak S, Orrego C, Marshall S (1999) Genetic monitoring by denaturant gel electrophoresis of Piscirickettsia salmonis, a bacterial disease of farmed salmonids. Tech Note 2451. Bio-Rad, Hercules, CA

Hepburn M, Miller GA (1998) A multiple mutation model system as a test development and training tool for denaturing gradient gel electrophoresis. Tech Note 2342. Bio-Rad, Hercules, CA 
Higuchi R, Watson R (1999) Kinetic PCR analysis using a CCD camera and without using oligonucleotide probes. In: Innis MA, Gelfand DH, Sninsky JJ (eds) PCR applications. Protocols for functional genomics. Academic Press, San Diego, p 263-284

House ML, Bartholomew JL, Winton JR, Fryer JL (1999) Relative virulence of three isolates of Piscirickettsia salmonis for coho salmon Oncorhynchus kisutch. Dis Aquat Org 35. $107-113$

Hovig E, Smith-Sørensen B, Brøgger A, Børresen AL (1991) Constant denaturant gel electrophoresis, a modification of denaturing gradient gel electrophoresis, in mutation detection. Mutation Res 262:63-71

Jones SRM, Markham RJF, Groman DB, Cusack RR (1998) Virulence and antigenic characteristics of a cultured Rickettsiales-like organism isolated from farmed Atlantic salmon Salmo salar in eastern Canada. Dis Aquat Org 33: $25-31$

Lannan CN, Fryer JL (1994) Extracellular survival of Piscirickettsia salmonis. J Fish Dis 17:545-548

Lannan CN, Winton JR, Fryer JL (1984) Fish cell lines: establishment and characterization of nine cell lines from salmonids. In Vitro 20:671-676

Lerman LS, Silverstein K (1987) Computational simulation of DNA melting and its application to denaturing gradient gel electrophoresis. Methods Enzymol 155:482-501

Marshall S, Heath S, Henríquez V, Orrego C (1998) Minimally invasive detection of Piscirickettsia salmonis in cultivated salmonids via the PCR. Appl Environ Microbiol 64: 3066-3069

Massana R, Murray AE, Preston CM, DeLong EF (1997) Vertical distribution and phylogenetic characterization of marine planktonic Archaea in the Santa Barbara Channel. Appl Environ Microbiol 63:50-56

Mauel MJ, Giovannoni SJ, Fryer JL (1996) Development of polymerase chain reaction assays for detection, identification, and differentiation of Piscirickettsia salmonis. Dis Aquat Org 26:189-195

Mauel MJ, Giovannoni SJ, Fryer JL (1999) Phylogenetic

Editorial responsibility: Carey Cunningham,

Aberdeen, Scotland, UK analysis of Piscirickettsia salmonis by $16 \mathrm{~S}$, internal transcribed spacer (ITS) and $23 \mathrm{~S}$ ribosomal DNA sequencing. Dis Aquat Org 35:115-123

Murray AE, Hollibaugh JT, Orrego C (1996) Phylogenetic compositions of bacterioplankton from two California estuaries compared by denaturing gradient gel electrophoresis of $16 \mathrm{~S}$ rDNA fragments. Appl Environ Microbiol 62:2676-2680

Myers RM, Sheffield VC, Cox DR (1989) Mutation detection by PCR, GC-clamps, and denaturing gradient gel electrophoresis. In: Erlich HA (ed) PCR technology. Principles and applications for DNA amplification. Stockton Press, New York, p 71-88

Olsen AB, Melby HP, Speilberg L, Evensen $\varnothing$, Håstein T (1997) Piscirickettsia salmonis infection in Atlantic salmon Salmo salar in Norway - epidemiological, pathological and microbiological findings. Dis Aquat Org 31:35-48

Parker LT, Zakeri H, Deng Q, Spurgeon S, Kwok PY, Nickerson DA (1996) AmpliTaq DNA polymerase, FS dye-terminator sequencing: analysis of peak height patterns. BioTechniques 21:694-699

Ridanpää M, Burvall K, Zhang LH, Husgafvel-Pursiainen K, Önfelt A (1995) Comparison of DGGE and CDGE in detection of single base changes in the hamster hprt and human $\mathrm{N}$-ras genes. Mutation Res 334:357-364

Sheridan GEC, Masters CI, Shallcross JA, Mackey BM (1998) Detection of mRNA by reverse transcription-PCR as an indicator of viability in Escherichia coli cells. Appl Environ Microbiol 64:1313-1318

Steinert M, Emödy L, Amann R, Hacker J (1997) Resuscitation of viable but nonculturable Legionella pneumophila Philadelphia JR32 by Acanthamoeba castellanii. Appl Environ Microbiol 63:2047-2053

Welsh J, McClelland M (1993) Characterization of pathogenic microorganisms by genomic fingerprinting using arbitrarily primed PCR. In: Persing DH, Smith TF, Tenover FC, White TJ (eds) Diagnostic molecular microbiology. Principles and applications. American Society for Microbiology, Washington, DC, p 595-602

Submitted: November 16, 1999; Accepted: January 25, 2000 Proofs received from author(s): May 11, 2000 